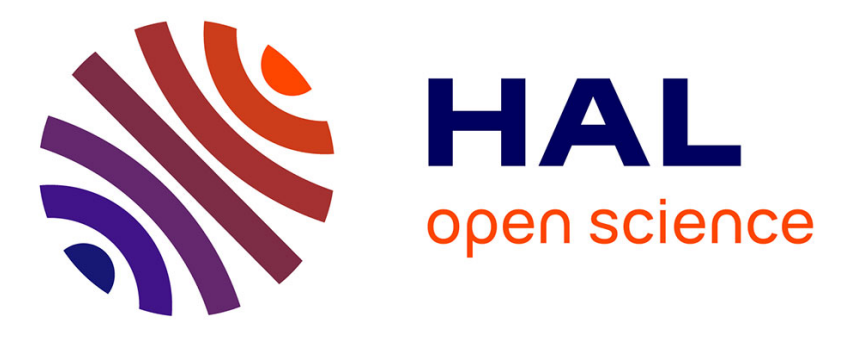

\title{
Production and Characterization of Alginate Microcapsules Produced by a Vibrational Encapsulation Device
}

\author{
S. Mazzitelli, A. Tosi, C. Balestra, C. Nastruzzi, G. Luca, F. Mancuso, R. \\ Calafiore, M. Calvitti
}

\section{To cite this version:}

S. Mazzitelli, A. Tosi, C. Balestra, C. Nastruzzi, G. Luca, et al.. Production and Characterization of Alginate Microcapsules Produced by a Vibrational Encapsulation Device. Journal of Biomaterials Applications, 2008, 23 (2), pp.123-145. 10.1177/0885328207084958 . hal-00570788

\section{HAL Id: hal-00570788 \\ https://hal.science/hal-00570788}

Submitted on 1 Mar 2011

HAL is a multi-disciplinary open access archive for the deposit and dissemination of scientific research documents, whether they are published or not. The documents may come from teaching and research institutions in France or abroad, or from public or private research centers.
L'archive ouverte pluridisciplinaire HAL, est destinée au dépôt et à la diffusion de documents scientifiques de niveau recherche, publiés ou non, émanant des établissements d'enseignement et de recherche français ou étrangers, des laboratoires publics ou privés. 


\title{
Production and Characterization of Alginate Microcapsules Produced by a Vibrational Encapsulation Device
}

\author{
S. Mazzitelli, A. Tosi, C. Balestra ANd C. Nastruzzi* \\ Department of Medicinal Chemistry and Pharmaceutics \\ University of Perugia, Perugia, Italy \\ G. LUCA, F. MANCUSO AND R. CALAFIORE \\ Department of Internal Medicine, Section of \\ Internal Medicine and Endocrine and Metabolic \\ Sciences, University of Perugia, Perugia, Italy \\ M. CALVITTI \\ Department of Experimental Medicine and Biochemical \\ Sciences, University of Perugia, Perugia, Italy
}

\begin{abstract}
The optimization, through a Design of Experiments (DoE) approach, of a microencapsulation procedure for isolated neonatal porcine islets (NPI) is described. The applied method is based on the generation of monodisperse droplets by a vibrational nozzle. An alginate/polyornithine encapsulation procedure, developed and validated in our laboratory for almost a decade, was used to embody pancreatic islets. We analyzed different experimental parameters including frequency of vibration, amplitude of vibration, polymer pumping rate, and distance between the nozzle and the gelling bath. We produced calcium-alginate gel microbeads with excellent morphological characteristics as well as a very narrow size distribution. The automatically produced microcapsules did not alter morphology, viability
\end{abstract}

\footnotetext{
*Author to whom correspondence should be addressed.

E-mail: nas@unipg.it ornas@biomaterials.it

Figures 2, 3, 8 and 9 appear in color online: http://jba.sagepub.com

JOURNAL OF BIOMATERIALS APPLICATIONS Volume 23 - September 2008 
and functional properties of the enveloped NPI. The optimization of this automatic procedure may provide a novel approach to obtain a large number of batches possibly suitable for large scale production of immunoisolated NPI for in vivo cell transplantation procedures in humans.

KEY WORDS: automatic encapsulator, design of experiment, alginate, neonatal porcine islets, biocompatibility.

\section{INTRODUCTION}

R ecent advances in cell biology, encapsulation technology, $\mathbf{1}$ and biomaterials sciences have led to the proposal that xenotransplantation procedures combined with an adapted immunoprotective strategy, may provide a solution to the shortage of human allografts. Cell encapsulation is a well-known technique for the entrapment of viable cells within a semi-permeable polymeric membrane. These membranes are usually formulated to permit small molecules such as nutrients to freely permeate into the microcapsule while blocking larger molecules and cells of the host immune system. Encapsulation allows the transplant of xenogenic or allogenic cells into a host to repair or replace damaged or diseased tissue without the need of immunosupressive regimens [1] that are often characterized by a number of adverse effects [2]. Most cell encapsulation devices are usually composed of polymers such as alginate, carrageenans, collagen, chitosan, cellulose, and agar/ agarose [3]. Among the polymers tested so far, alginate has been and will continue to be one of the most important encapsulating material. Alginate cross-linked with $\mathrm{Ca}$ or $\mathrm{Ba}$ ions has been used successfully to encapsulate cells and to maintain their function in tissue culture $[4,5]$.

Alginates possess the ability to form gels in very mild conditions by reaction of divalent cations with guluronic acid blocks in alginate, the gelation behavior is based on alginate's ability to bind these ions in a selective and cooperative fashion [6].

The use of alginate is favored because of its cheapness and biocompatibility. Cells immobilized in alginate gels maintain good viability during long-term culture due to the mild environment of the gel network.

Numerous cell encapsulation techniques have been developed over the years including among others: spinning disk atomization, coaxial airflow dropping, jetcutter technology, and electrostatic droplet generation technology [7]. 
Table 1. Production of alginate microcapsules by vibrational encapsulation procedure: the investigated experimental parameters and their range of variation.

\begin{tabular}{|c|c|c|c|}
\hline Parameter & Abbrevation & Meaning & Range \\
\hline Frequency & Freq & $\begin{array}{l}\text { Frequency of the vibration } \\
\text { of the nozzle }\end{array}$ & $100-500 \mathrm{~Hz}$ \\
\hline Amplitude & Amp & Amplitude of vibration of the nozzle & $2-6 \mathrm{~mm}$ \\
\hline Pump & Pump & Polymer pumping rate & $9.96-11.76 \mathrm{~mL} / \mathrm{min}$ \\
\hline Height & Height & $\begin{array}{l}\text { Distance between the nozzle } \\
\text { and the gelling surface of the } \\
\text { gelling bath }\end{array}$ & $40-100 \mathrm{~mm}$ \\
\hline
\end{tabular}

The present paper is intended to describe the optimization, by a factorial design approach, of a method based on the application of a semi-automated instrument for the encapsulation of neonatal porcine islets (NPI) into alginate microcapsules, which is commercialized by Inotech Encapsulation [8]. The Encapsulator from Inotech is a vibrating nozzle device capable of producing microcapsules under sterile working conditions. The bead formation is based on the fact that a laminar liquid flow is broken up into equal beads, if it is vibrated at an optical frequency. Up until now in the literature there are no papers describing an accurate statistical analysis of the performances of a vibrating nozzle instrument by experimental design approach. Therefore, in order to have a better understanding of the process, the correlations between the experimental set up of the instrument (frequency, amplitude, pump, and height see Table 1) and the dimensional and morphological characteristics of the produced microcapsules were evaluated. Special attention will be paid to fix the experimental set up resulting in the formation of uniform spherical smooth microcapsules [5].

\section{MATERIALS}

The polymer used for microparticle preparation was ultrapure sodium alginate NAG from Kelco Biopolymers (UK). A 2\% (w/v) aqueous solution of NAG has the following characteristics: MW 120,000/ $190,000 \mathrm{kDa}$; content of $\mathrm{M} 61 \%$ and $\mathrm{G} 39 \%$, viscosity $100 / 130$ (Brookfield $25^{\circ} \mathrm{C}, 60 \mathrm{rpm}$ ), $\mathrm{pH}$ 6.4-8.0, endotoxin level $39 \mathrm{EU} / \mathrm{g}$, as provided by the manufacturer. Before use, NAG solutions were successively filtered by a stainless steel pressure holder from Sartorius 
(Germany) equipped with $0.8,0.45$, and $0.22 \mu \mathrm{m}$ cellulose acetate membranes.

The cation used for the ionic gelation was calcium chloride diydrate from Sigma-Aldrich (Germany). Poly-L-ornithine (PLO) was purchased from Sigma-Aldrich (Germany).

\section{METHODS}

\section{Production of Alginate Microcapsules by a Vibrating-nozzle Procedure}

Monodisperse alginate beads were prepared using an encapsulation device based on a vibrating-nozzle (Encapsulator Research Inotech, Dottikon Switzerland) and the experimental procedure described elsewhere [9]. This system is composed (Figure 1) of a 2-liter glass reaction vessel with stainless steel top and bottom plates. The top plate contains a feed-line connected to a syringe or hydraulic polymer reservoir and a nozzle. A nozzle with an internal diameter of $300 \mathrm{~mm}$ was used. The nozzle is connected, via a steel or PTFE membrane, to a vibrating device, which is insulated from the surrounding structures by rubber mounts to avoid the generation of resonance frequencies in the system. The flow of alginate to the nozzle is achieved by a precision syringe.

Different calcium alginate microcapsules were produced by changing the reported experimental parameters following an experimental design and statistical analysis: the vibrational frequency ('freq'), the vibrational amplitude ('amp'), the alginate pumping rate ('pump'), and the distance between the nozzle and the surface of the gelling bath ('height') (Table 1).

\section{Dimensional and Morphological Characterization of Microcapsules}

The morphology of alginate microbeads was evaluated by optical-stereomicroscopy (Nikon SMZ 1500 stereo microscope, Tokio, Japan). Microcapsule size and size distribution (by number) were determined by photomicrograph analyses (Eclipsenet version 1.16.5, Laboratory Imaging s.r.o. for Nikon B.V.).

In this technique, bead samples, immediately after preparation and at intervals after storage under different conditions, were applied to a microscope slide and examined microscopically. 


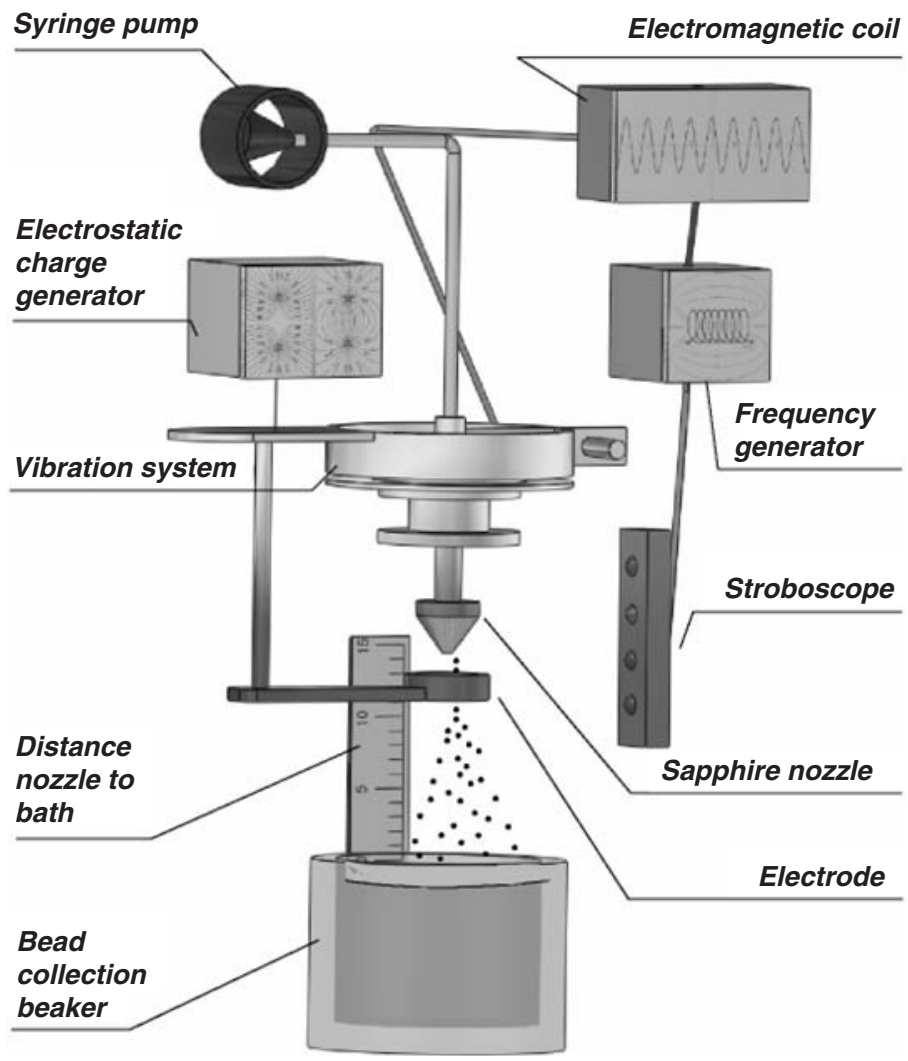

Figure 1. Schematic representation of an encapsulation device based on a vibrating nozzle used in the present study.

A sample of 100-300 beads was examined, and the mean size was determined.

\section{Experimental Design and Statistical Analysis}

For studying the effect and the influence of different experimental parameters (i.e., frequency, pump, and height) on the dimensional and morphological characteristics of alginate microcapsules, a randomized central composite face-centered design (CCF) consisting of 16 runs was used. The parameters were varied as reported in the experimental matrix (Tables 2 and 3). The experimental design 
Table 2. Experimental design matrix and results of the DoE (Design of Experiments) approach for empty microbeads.

\begin{tabular}{lccccc}
\hline Factors & & & & \multicolumn{2}{c}{ Responses } \\
\cline { 1 - 3 } $\begin{array}{l}\text { Frequency } \\
(\mathrm{Hz})\end{array}$ & $\begin{array}{c}\text { Pump } \\
(\mathrm{mL} / \mathrm{min})\end{array}$ & $\begin{array}{c}\text { Nozzle to bath } \\
(\mathrm{mm})\end{array}$ & & $\begin{array}{c}\text { Tails } \\
(\%)\end{array}$ & $\begin{array}{c}\text { Coalescences } \\
(\%)\end{array}$ \\
\hline 500 & 9.96 & 40 & & 6.7 & 8.2 \\
1300 & 9.96 & 40 & & 9.5 & 8.5 \\
500 & 11.76 & 40 & & 8.3 & 8.9 \\
1300 & 11.76 & 40 & & 7.9 & 8.5 \\
500 & 9.96 & 100 & & 10.2 & 10.2 \\
1300 & 9.96 & 100 & & 10.7 & 9.7 \\
500 & 11.76 & 100 & & 10.3 & 9.7 \\
1300 & 11.76 & 100 & & 10.1 & 8.9 \\
500 & 10.86 & 70 & & 10.7 & 10.6 \\
1300 & 10.86 & 70 & & 9.9 & 9.6 \\
900 & 9.96 & 70 & & 9.1 & 9.3 \\
900 & 11.76 & 70 & & 8.5 & 9.2 \\
900 & 9.96 & 40 & & 0.3 & 0.8 \\
900 & 9.96 & 100 & 5 & 2.4 \\
900 & 9.96 & 70 & 4.9 & 4.8 \\
900 & 9.96 & 70 & 4.7 & 4.3 \\
\hline
\end{tabular}

Data represent the average of three independent determinations.

Table 3. Experimental design matrix and results of the DoE (Design of Experiments) approach for NPI containing microcapsules.

\begin{tabular}{lccccc}
\hline Factors & & & & \multicolumn{2}{c}{ Responses } \\
\cline { 1 - 3 } $\begin{array}{l}\text { Frequency } \\
(\mathrm{Hz})\end{array}$ & $\begin{array}{c}\text { Pump } \\
(\mathrm{mL} / \mathrm{min})\end{array}$ & $\begin{array}{c}\text { Nozzle to bath } \\
(\mathrm{mm})\end{array}$ & & $\begin{array}{c}\text { Tails } \\
(\%)\end{array}$ & $\begin{array}{c}\text { Coalescences } \\
(\%)\end{array}$ \\
\hline 100 & 7.7 & 100 & & 9.0 & 9.8 \\
200 & 7.7 & 100 & & 9.1 & 10.0 \\
100 & 9.5 & 100 & & 8.3 & 8.9 \\
200 & 9.5 & 100 & & 8.8 & 9.0 \\
100 & 7.7 & 140 & & 6.9 & 7.8 \\
200 & 7.7 & 140 & & 7.0 & 8.0 \\
100 & 9.5 & 140 & & 6.8 & 7.9 \\
200 & 9.5 & 140 & & 6.7 & 7.5 \\
100 & 8.6 & 120 & & 6.9 & 7.8 \\
200 & 8.6 & 120 & & 6.6 & 7.9 \\
150 & 7.7 & 120 & & 6.0 & 6.4 \\
150 & 9.5 & 120 & 6.5 & 7.0 \\
150 & 8.6 & 100 & & 4.3 & 4.5 \\
150 & 8.6 & 140 & & 0.9 & 3.1 \\
150 & 8.6 & 120 & 3.1 & 3.6 \\
150 & 8.6 & 120 & 2.9 & 4.9 \\
\hline
\end{tabular}

Data represent the average of three independent determinations. 
and the evaluation of the experiments were performed by the PC software MODDE 8.0 (Umetrics AB, Sweden), followed by multiple linear regression (MLR) algorithms.

\section{NPI Isolation}

Neonatal 'large-white' pigs, aged 3 or 12 days, were used for pancreatic donors. NPI were isolated according to previously established methods [10,11]. Briefly, the piglets anesthetized with $0.1 \mathrm{mg} / \mathrm{Kg}$ azaperon (Stresnil ${ }^{\circledR} 40 \mathrm{mg} / \mathrm{mL}$, Janssen, Belgium) and $15 \mathrm{mg} / \mathrm{Kg}$ ketamine (Imalgene ${ }^{\circledR} 100 \mathrm{mg} / \mathrm{mL}$, Gellini Farmaceutici, Italy) were co-administered intramuscularly. The piglets underwent total laparotomy, by midline incision, for carefully excising the pancreas. In order to prevent bacterial contamination, particular care was taken to avoid bowel nicking. Upon transportation to the laboratory in cold Eurocollins (SALF, Italy), the pancreas was cut into small pieces $\left(1-3 \mathrm{~mm}^{3}\right)$ and washed in Hank's balanced salt solution (HBSS) (Sigma Chemical Co, USA). The tissue was digested by mild shaking in $2 \mathrm{mg} / \mathrm{mL}$ collagenase $\mathrm{P}$ solution (Roche Diagnostics, S.p.A., Italy), for $5 \mathrm{~min}$, at room temperature, and thereafter for additional $15 \mathrm{~min}$, at $37^{\circ} \mathrm{C}$. The digest was centrifuged at $500 \mathrm{rpm}$ for $5 \mathrm{~min}$, and subsequently washed twice in HBSS (Sigma) supplemented with $100 \mathrm{U} / \mathrm{mL}$ penicillin $+0.1 \mathrm{mg} / \mathrm{ml}$ streptomycin (Sigma). Finally, the tissue was resuspended in HAM-F-12 supplemented with $0.5 \%$ bovine serum albumin, fraction V (Sigma), $\quad 50 \mu \mathrm{M} \quad 3$-isobutyl-1-methylxanthine (IBMX) (Sigma), $10 \mathrm{mM}$ nicotinamide (Sigma), $2 \mathrm{mM}$ L-glutamine (Sigma), $100 \mathrm{U} / \mathrm{mL}$ penicillin $+0.1 \mathrm{mg} / \mathrm{mL}$ streptomycin (Sigma) and plated in $100 \times 15 \mathrm{~mm}$ Petri dishes (Becton Dickinson Labware, Lincoln Park, NY) $(10,000$ NPI/plate). The culture medium was changed every $48 \mathrm{~h}$.

\section{Encapsulation of NPI by Inotech Encapsulator}

Before encapsulation, in vitro cultured NPI were suspended in HBSS and added to a sodium alginate solution resulting in a final concentration of $1.6 \%(\mathrm{w} / \mathrm{v})$. Afterwards, this suspension was pumped to the encapsulator by a syringe pump and separated into equal sized droplets by the vibrating nozzle. The generated microdroplets were allowed to fall into an isotonic calcium chloride solution $(1.2 \% ; \mathrm{w} / \mathrm{v})$ placed at $140 \mathrm{~mm}$ from the vibrating nozzle. After gelification ( $5 \mathrm{~min}$ ) of the microdroplets in the calcium containing gelling bath, the microbeads were washed twice with an isotonic solution and coated with $0.12 \%(\mathrm{w} / \mathrm{v})$ poly-ornithine solution for $10 \mathrm{~min}$. During this step 
the polycations bind to the negatively charged carboxyl groups on the alginate capsules surface enabling the formation of a hydrogel surrounding the capsules. Subsequently, the coated microcapsules were incubated with a low concentration poly-ornithine solution (at lower concentration, $0.06 \%$; w/v). Finally, the uncomplexed polycations on the microcapsules surface were complexed with a dilute alginate solution for biocompatibility improvement [5].

\section{In Vitro Assessment of Encapsulated NPI}

After encapsulation, in vitro cultured NPI (both free and encapsulated), were examined for viability, morphology, maturation, and insulin secretion, as previously reported [10].

Briefly, at day 7 of culture (after encapsulation), viability was performed by staining the preparations with ethidium bromide (EB) (Sigma) and fluorescein-diacetate (FDA) (Sigma) [12]. Cells were visualized under fluorescence microscope (Nikon, Optiphot-2, Nikon Corporation, Japan) using the filter block for fluorescein. Dead cells were stained in red, while viable ones appeared in green.

Encapsulated NPI were also tested (day 7) for insulin secretion capacity as follows. Batches of 50 hand-picked NPI (from NPI cultures in $100 \times 20 \mathrm{~mm}^{2}$ Petri dishes) were sequentially exposed to glucose at different concentrations $(2.8-16.7-2.8 \mathrm{mmol} / \mathrm{dL})$ in a $2 \mathrm{~h}$ static incubation system. Briefly, the culture medium was replaced with low-glucose-containing $(2.8 \mathrm{mmol} / \mathrm{L}) \mathrm{HAM}$ F12 medium without serum for $2 \mathrm{~h}$; then with high-glucose-containing $(16.7 \mathrm{mmol} / \mathrm{L})$ HAM F12 for another $2 \mathrm{~h}$; and then again changed to HAM F12 with low glucose (further $2 \mathrm{~h}$ ); after each treatment the cells were washed with Krebs solution supplemented with $1 \%$ bovine serum albumin.

Insulin content was determined by radioimmunoassay (intra-assay $\mathrm{CV}<5.5 \%$; inter-assay $\mathrm{CV}=9.0 \%$ ). In addition encapsulated NPI were stained with diphenylthiocarbazone (DTZ) (insulin content) commonly used to identify beta cells.

\section{Transplant Procedure and Biocompatibility Assessment}

Under general anesthesia, induced by intra-peritoneal administration of $100 \mathrm{mg} / \mathrm{Kg}$ ketamine (Parke-Davis/Pfizer, Germany) and $15 \mathrm{mg} / \mathrm{Kg}$ xylazine (Bayer, Germany), the microencapsulated NPI were collected by a sterile transfer pipette and delivered into the peritoneal cavity of three recipient rabbits through a small abdominal incision. 
After 15 weeks, the transplanted animals were anesthetized as previously described, to explant the microcapsules by peritoneal lavage with warm saline. General characteristics of the retrieved microcapsules were determined by examining extent of the fibrotic overgrowth under phase contrast microscopy, morphology such as microcapsules sphericity and surface smoothness, and finally by staining the encapsulated cells with EB + FDA (cell viability).

\section{RESULTS AND DISCUSSION}

\section{Production of Alginate Microbeads: Intuitive COST Approach}

In a preliminary phase of this study, a classical intuitive approach COST, (Changing One Separate factor a Time) was employed to define the experimental planning, including the selection of the crucial experimental parameters. Indeed, this approach was chosen in order to evaluate, which factor(s) could more deeply affect the production of the alginate microcapsules in terms of general geometry, surface characteristics, and dimension.

Following this experimental approach, only one experimental parameter was varied at a time (Table 1), while all the others were maintained constant. We conducted the experiments changing the following parameters: frequency of vibration (freq), amplitude of vibration (amp), polymer pumping rate (pump), and distance between the nozzle and the gelling bath (height).

The frequency was calculated from a knowledge of the alginate solution properties for the nozzle diameter used [8]. In spite of this, during the experiments some changes were performed, to obtain the desired microbeads size and morphology (mean diameter comprised between 550 and $650 \mu \mathrm{m}$ with a spherical shape). The vibrating frequency of the nozzle was varied from 500 to $1300 \mathrm{~Hz}$, while the rate of polymer pumping was investigated in the range $9.96-11.76 \mathrm{~mL} / \mathrm{min}$ (Table 4). The investigation of these parameters revealed that increasing both factors led to a decrease of particle size (Figure 2(b)-(e)), but if the vibrating frequency was set too high $(>1000 \mathrm{~Hz})$ a progressive number of coalescences (formation of clusters of microbeads partially fused together) was detectable in the microbead population (see arrows in Figure 2(c)).

The amplitude of the vibration applied to the nozzle (varied in a range from 2 to $6 \mathrm{~mm}$ ) had only a slight effect on the microbead characteristic (Table 4). On the contrary, the distance between the nozzle and the gelling bath (range $40-100 \mathrm{~mm}$ ) has a great 
Table 4. COST (Changing One Separate factor a Time) analysis of the effect of the 'freq', 'amp', 'pump', and 'height' on microbead characteristics.

\begin{tabular}{|c|c|c|c|c|c|c|c|}
\hline $\begin{array}{l}\text { Alginate } \\
(w / v, \%)\end{array}$ & $\begin{array}{l}\text { Frequency } \\
(\mathrm{Hz})\end{array}$ & $\begin{array}{c}\text { Amplitude } \\
(\mathrm{mm})\end{array}$ & $\begin{array}{l}\text { Pump } \\
\text { (mL/min) }\end{array}$ & $\begin{array}{l}\text { Height } \\
(\mathrm{mm})\end{array}$ & $\begin{array}{l}\text { Tails } \\
(\%)\end{array}$ & $\begin{array}{c}\text { Coalesc. } \\
(\%)\end{array}$ & Surface \\
\hline \multicolumn{8}{|l|}{ Freq } \\
\hline 1.6 & 500 & 6 & 10.86 & 40 & $2-5$ & $5-10$ & Some wrinkles \\
\hline 1.6 & 700 & 6 & 10.86 & 40 & $2-5$ & $2-5$ & Some wrinkles \\
\hline 1.6 & 900 & 6 & 10.86 & 40 & $<2$ & $<2$ & Smooth \\
\hline 1.6 & 1100 & 6 & 10.86 & 40 & $5-10$ & $2-5$ & Some wrinkles \\
\hline 1.6 & 1300 & 6 & 10.86 & 40 & $>10$ & $5-10$ & Irregular \\
\hline \multicolumn{8}{|l|}{ Amp } \\
\hline 1.6 & 900 & 2 & 10.86 & 40 & $2-5$ & $2-5$ & Some wrinkles \\
\hline 1.6 & 900 & 4 & 10.86 & 40 & $2-5$ & $<2$ & Smooth \\
\hline 1.6 & 900 & 6 & 10.86 & 40 & $<2$ & $<2$ & Smooth \\
\hline \multicolumn{8}{|l|}{ Pump } \\
\hline 1.6 & 900 & 6 & 9.96 & 40 & $5-10$ & $5-10$ & Some wrinkles \\
\hline 1.6 & 900 & 6 & 10.41 & 40 & $2-5$ & $2-5$ & Smooth \\
\hline 1.6 & 900 & 6 & 10.86 & 40 & $<2$ & $<2$ & Smooth \\
\hline 1.6 & 900 & 6 & 11.31 & 40 & $2-5$ & $5-10$ & Smooth \\
\hline 1.6 & 900 & 6 & 11.76 & 40 & $2-5$ & $5-10$ & Some wrinkles \\
\hline 1.6 & 900 & 6 & 11.76 & 40 & $2-5$ & $5-10$ & Very irregular \\
\hline \multicolumn{8}{|l|}{ Height } \\
\hline 1.6 & 900 & 6 & 10.86 & 100 & $5-10$ & $2-5$ & Smooth \\
\hline 1.6 & 900 & 6 & 10.86 & 70 & $2-5$ & $2-5$ & Smooth \\
\hline 1.6 & 900 & 6 & 10.86 & 40 & $<2$ & $<2$ & Smooth \\
\hline \multicolumn{8}{|l|}{ Selected } \\
\hline 1.6 & 900 & 6 & 10.86 & 40 & $<2$ & $<2$ & Smooth \\
\hline
\end{tabular}

The morphological characteristics of microcapsules were assessed on at least 200 microcapsules/ batch, considering the presence of (a) tails, (b) coalescences and (c) the surface characteristic. All the reported preparations were performed by a $60 \mathrm{~mL}$ syringe.

Data represent the average of three independent determinations on different microbead batches.

effect on the microbead morphology. In fact, increasing the distance from 40 to $100 \mathrm{~mm}$ caused the progressive formation of microbead with an elliptic shape (formation of tails, Figure $2(\mathrm{f})-(\mathrm{g})$ ). Considering the results of this preliminary set of experiments (summarized in Table 4), we conclude that among the four different experimental variables only the amplitude of the vibration has minor effect on the microbeads formation, while all the others exert significant morphological and dimensional changes on the alginate particles.

For this reason in the second part of the investigation we decided to focus our attention on the parameters: freq, pump, and height. 

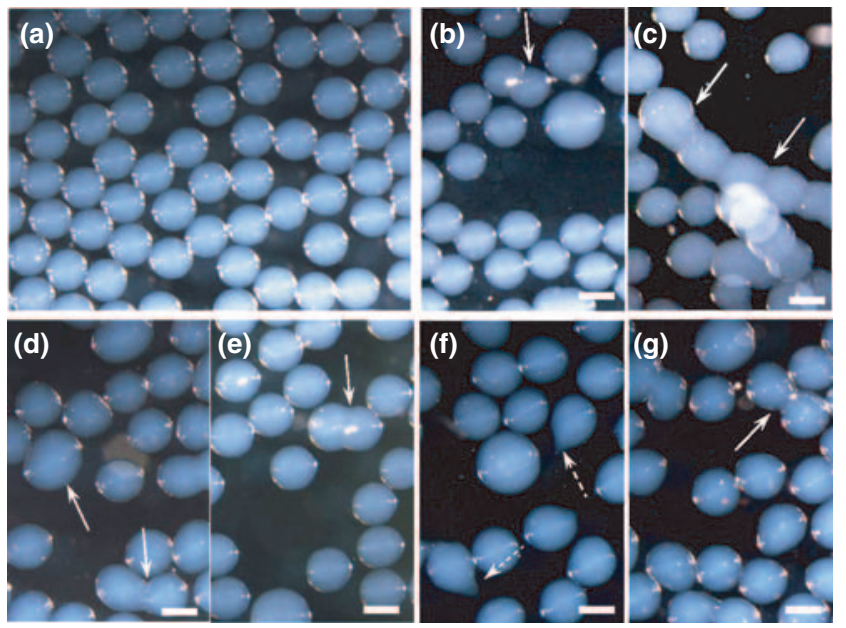

Figure 2. Optical photomicrographs of empty alginate microbeads prepared by vibrational encapsulator. Effect of different parameters on microcapsules characteristics. In panel (a) are depicted the microcapsules prepared using the optimized parameters (Table 4). Panels (b) and (c): effect of the vibrational frequency, (b): $1100 \mathrm{~Hz},(\mathrm{c}): 1300 \mathrm{~Hz}$; panels (d) and (e): effect of the pump, (d): $11.31 \mathrm{~mL} / \mathrm{min},(e): 11.76 \mathrm{~mL} / \mathrm{min}$; panels (f) and (g): effect of the height, (f): $70 \mathrm{~mm},(\mathrm{~g}): 100 \mathrm{~mm}$. Plain arrows indicate clusters of partially fused microcapsules (partial coalescences); dashed arrows indicate microcapsules showing tails or irregular morphology.

\section{Effect of Alginate Concentration on Microcapsule Characteristics}

Once the main instrumental parameters were selected, we focused our attention on another important experimental setting: the alginate concentration. Different concentrations were selected, ranging from 0.5 to $3 \%(\mathrm{w} / \mathrm{v})$ and the effect on the possible production of microbeads was considered as well (Table 5).

As first observation, it should be mentioned that, using the automated vibrating nozzle instrumentation, we could succeed in obtaining microbeads using alginate concentration up to $2.0 \%(\mathrm{w} / \mathrm{v})$. On the contrary, using higher concentrations of alginate $(>2.0 \%$, w/v), the resulting solution was too viscous to be efficiently transformed into microdroplets.

After production, samples of alginate microcapsules were withdrawn from the gelling bath in order to evaluate their morphology, size and size distribution. 
Table 5. COST (Changing One Separate factor a Time) analysis of the effect of alginate concentration on microbead characteristics.

\begin{tabular}{|c|c|c|c|c|c|}
\hline Batch & $\begin{array}{l}\text { Alginate } \\
(w / v, \%)\end{array}$ & $\begin{array}{l}\text { Flow } \\
(\mathrm{mL} / \mathrm{min})\end{array}$ & $\begin{array}{l}\text { Production } \\
\text { time }\end{array}$ & $\begin{array}{l}\text { Mean diameter } \\
\quad \pm \mathrm{SD}(\mu \mathrm{m})\end{array}$ & Notes \\
\hline A1 & 0.5 & 10.86 & $10 \mathrm{~s}$ & $618 \pm 35$ & $\begin{array}{l}\text { Moderate sphericity, some } \\
\text { coalescences }\end{array}$ \\
\hline A2 & 1.0 & 10.86 & $10 \mathrm{~s}$ & $640 \pm 28$ & $\begin{array}{l}\text { Good sphericity, not much } \\
\text { coalescences }\end{array}$ \\
\hline A3 & 1.5 & 10.86 & $10 \mathrm{~s}$ & $559 \pm 18$ & $\begin{array}{l}\text { Good sphericity and } \\
\text { dimensional distribution }\end{array}$ \\
\hline A4 & 2.0 & 10.86 & $10 \mathrm{~s}$ & $691 \pm 21$ & $\begin{array}{l}\text { Good sphericity rare } \\
\text { coalescence }\end{array}$ \\
\hline A5 & 2.5 & NA & NA & NA & $\begin{array}{l}\text { Impossible to produce microcapsules, } \\
\text { the solution is too viscous }\end{array}$ \\
\hline A6 & 3.0 & NA & NA & NA & $\begin{array}{l}\text { Impossible to produce microcapsules, } \\
\text { the solution is too viscous }\end{array}$ \\
\hline
\end{tabular}

Data represent the average of three independent determinations on different microbead batches.

Optical microscopic examination of the beads produced with an alginate concentration comprised between 1.0 and 2.0\% (w/v) (Figure 3) showed that they were spherical in shape and characterized by a smooth surface. Lowering the alginate concentration down to $0.5 \%(\mathrm{w} / \mathrm{v})$ caused partial broke-up of capsules (see dotted arrows in Figure 3(a)) resulting in particles with a irregular shape. This behavior was attributed to the mechanical stress caused by the landing in the hardening solution. Moreover, at the same concentration, some coalescences were detectable (Figure. 3(a)). As shown in the Figure 3 and in Table 5, we obtained alginate microcapsules with a smaller mean diameter and homogenous dimensional distribution using a polymer concentration of $1.5 \%(\mathrm{w} / \mathrm{v})$. With increasing the concentration up to $2 \%(\mathrm{w} / \mathrm{v})$, the size distribution became broader and the mean diameter increased from 559 (in the case of an alginate concentration of 1.5\%) to $691 \mu \mathrm{m}$ (Table 5). From the analysis of the results reported in Table 5 , it was evident that alginate microcapsules prepared with a concentration of 0.5 and $1.0 \%(\mathrm{w} / \mathrm{v})$ formed some coalescences (see arrows in Figure 3), although the size distribution remained acceptably narrow.

\section{Production of Alginate Microbeads: Design of the Experiments (DoE) Approach}

After having carried out the COST approach, a 'DoE' optimization and screening of the experimental parameters were performed. The DoE 

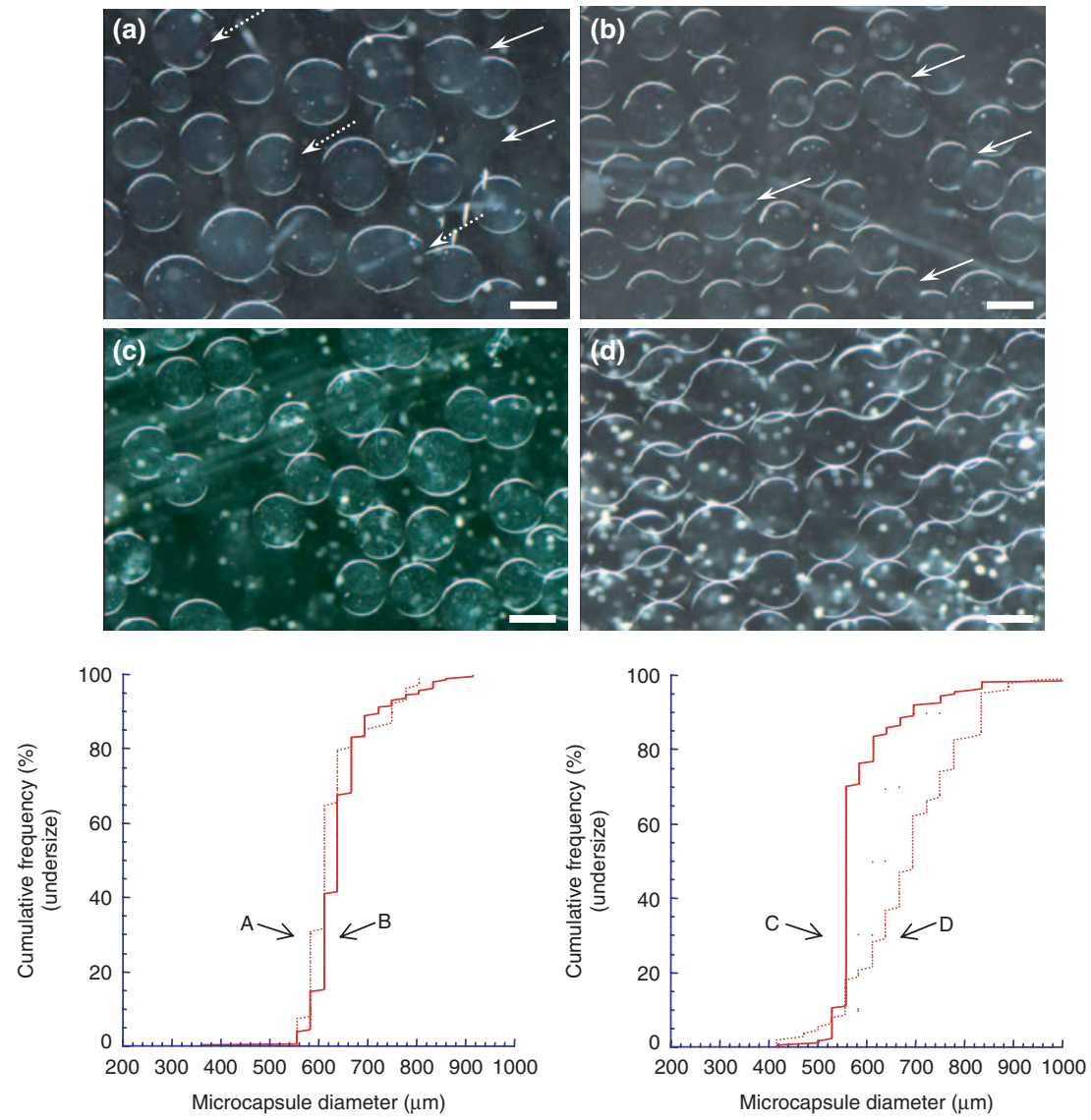

Figure 3. Optical photomicrographs of empty alginate microbeads prepared by vibrational encapsulator (top) and cumulative size distribution analysis (bottom). Effect of the different alginate concentrations on the morphological and dimensional characteristics of alginate microcapsules. The samples were prepared with an alginate concentration of 0.5 (a), 1 (b), 1.5 (c), and $2 \%$ (w/v) (d). Plain arrows indicate clusters of partially fused microcapsules (partial coalescences); dotted arrows indicate broken microcapsules.

offers a rational approach that enhances the value of the research, reducing the number of experiments and providing much more information about the effects of different variables and their possible interactions [13].

For performing the factorial design test, the parameters frequency, pump, and height were chosen as variables and tested at three levels (Table 2). For three variables with three levels for each, there 
are $3^{3}$ or 27 possible combinations in a full factorial design. In our case, we selected 14 experiments by a randomized CCF, which requires fewer trials [14]. We also added two center points in order to have an estimation of the experimental error. In this way we obtained both a non linear response and a response surface modeling (RSM).

The MLR equation (Equation (1)) for the responses of the chosen model is reported below:

$$
\begin{aligned}
y_{i}= & \text { Constant }+A_{1} F+A_{2} P+A_{3} H+A_{4} F^{2}+A_{5} P^{2} \\
& +A_{6} H^{2}+A_{7} F P+A_{8} F H+A_{9} P H
\end{aligned}
$$

where constant is the mean of the 16 runs and $A i$ the regression coefficients of the factors and their interactions.

By examining the results the main observation was that a change in height value from low to high level $(40-100 \mathrm{~mm})$ results in an increase of tail formation as well as of coalescences. On the other hand, the freq and pump parameters exert an influence in their high and low levels causing the increase of the both responses (Table 2).

Both two-dimensional and three-dimensional graphs of the investigated factors are given in the Figures 4 and 5, respectively, showing the influence of factors on tails (Figure 4) and coalescences formation (Figure 5).

After investigation of the factors influence, the validity and the significance of the model was estimated by analysis of variance (ANOVA). All the data obtained fitted well the model determining a good reproducibility of the studied model. We get a large regression coefficient $R^{2}$ that results a necessary condition for a validity model with a significant power of prediction of the model $Q^{2}$ (Table 6 ).

\section{Encapsulation of NPI in Alginate Microcapsules}

Once obtained alginate microcapsules with a satisfactory morphology through the application of DoE approach, we started a new series of experiments aimed to the encapsulation of NPI.

The first problem was to find the optimal parameters for achieving a continuous and stable polymer flow. It should be mentioned that the presence of the cells (NPI) created a break-up of droplets flow perhaps due to a partial nozzle occlusion. Another crucial factor to investigate was the ratio between cells and the alginate solution in order to obtain beads with an optimal islet density.

The performed experiments demonstrated that the parameter values for producing alginate microcapsules containing NPI were 

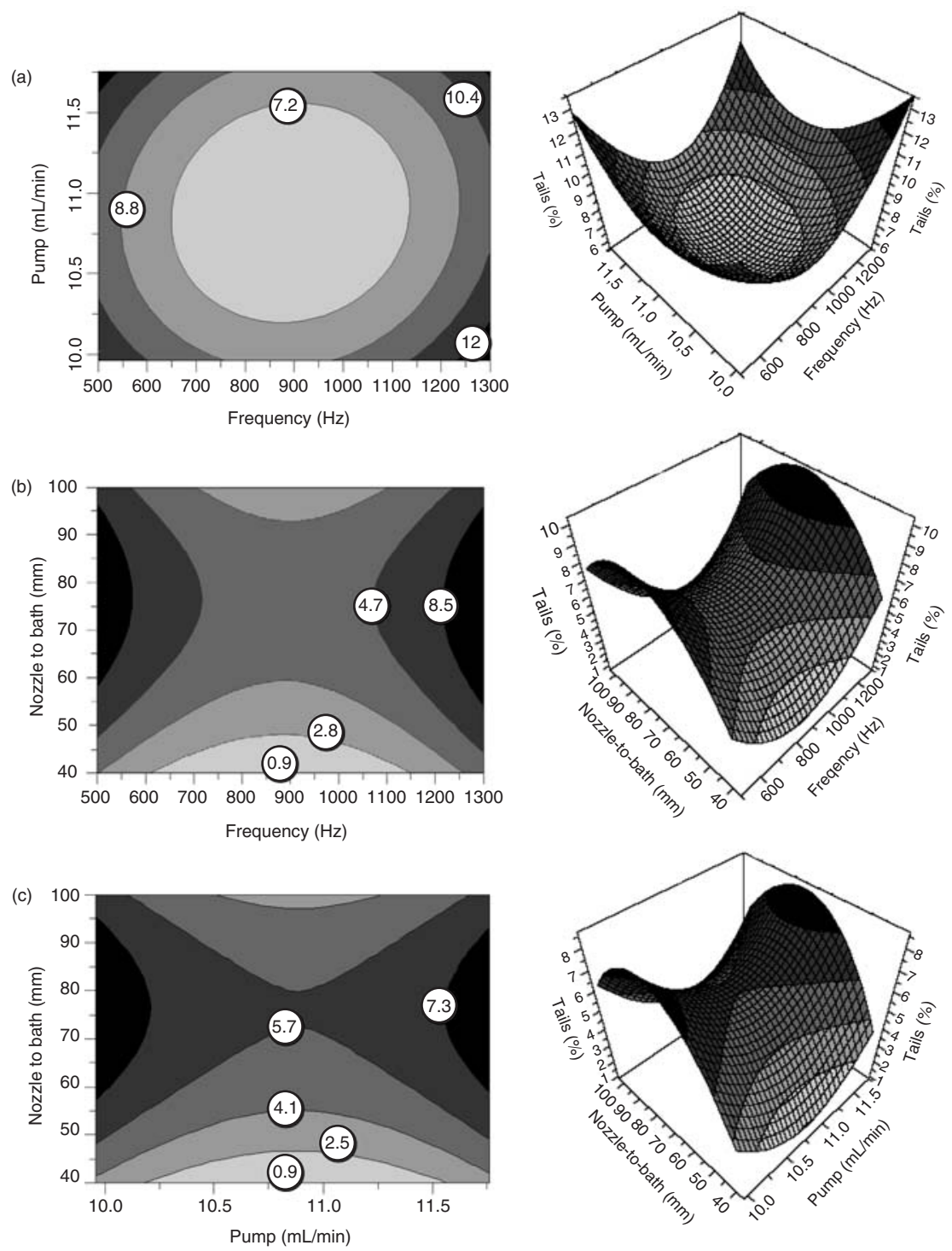

Figure 4. DoE analysis for empty alginate microbeads. Contour plots (left side) and the corresponding response surface plots (right side) of the response 'tails' for the interaction between pump and vibrating frequency (a), nozzle to bath and vibrating frequency (b), and nozzle to bath and pump (c). 
(a)
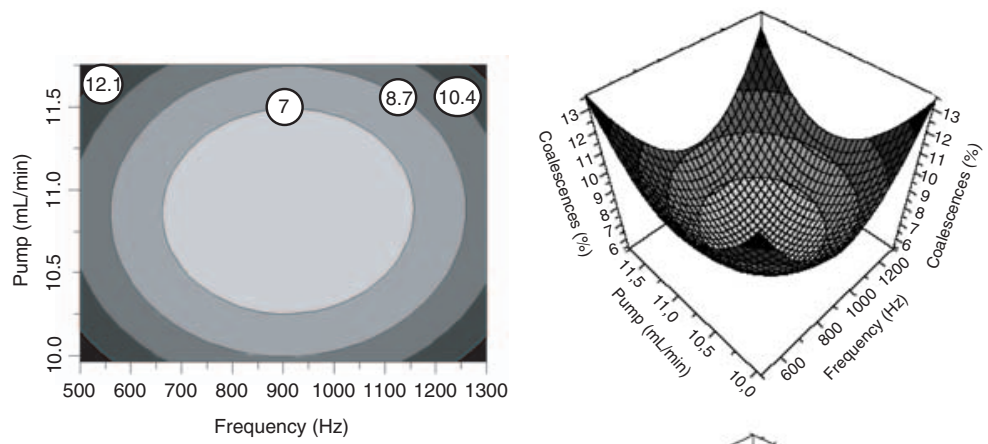

(b)
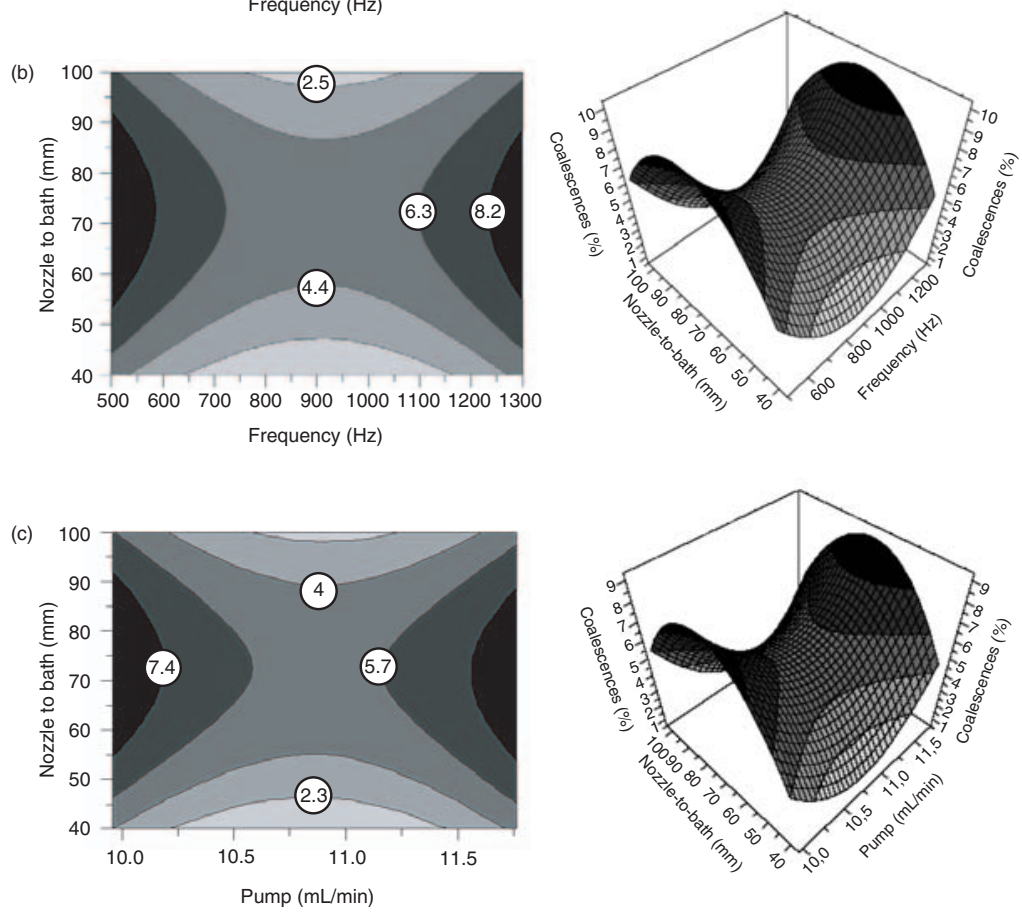

Figure 5. DoE analysis for empty alginate microbeads. Contour plots (left side) and the corresponding response surface plots (right side) of the response 'coalescences' for the interaction between pump and vibrating frequency (a), nozzle to bath and vibrating frequency (b), and nozzle to bath and pump (c).

lower than the values optimized by the COST and the DoE studies for the empty microbeads. In particular, it was evidenced, performing a COST study for NPI containing alginate/polyornithine microcapsules, that the vibrating frequency and the amplitude should be reduced for supplying a regular and constant flow (Table 8). 
Table 6. ANOVA analysis of variance of the model for the DoE approach (Design of Experiments) for empty microbeads.

\begin{tabular}{lcccccccc}
\hline & $N$ & $R^{2}$ & $R^{2}$ Adj. & $Q^{2}$ & SDY & RSD & Model validity & Reproducibility \\
\hline Coalescences & 16 & 0.948 & 0.854 & 0.844 & 3.011 & 1.147 & 0.375 & 0.997 \\
Tails & 16 & 0.980 & 0.946 & 0.048 & 3.063 & 0.706 & 0.722 & 0.986 \\
\hline
\end{tabular}

$N$ is the number of experiments.

$R^{2}$ is the percent of the variation of the response explained by the model.

$R^{2} \mathrm{Adj}$ is the fraction of the variation of the response explained by the model adjusted for the degree of freedom.

$Q^{2}$ is the percent of the variation of the response predicted by the model.

Table 7. ANOVA analysis of variance of the model for the DoE approach (Design of Experiments) for NPI containing microcapsules.

\begin{tabular}{lcccccccc}
\hline & $N$ & $R^{2}$ & $R^{2}$ Adj. & $Q^{2}$ & SDY & RSD & Model validity & Reproducibility \\
\hline Coalescences & 16 & 0.859 & 0.648 & 0.441 & 2.414 & 1.432 & 0.726 & 0.914 \\
Tails & 16 & 0.847 & 0.619 & 0.019 & 1.832 & 1.129 & 0.842 & 0.748 \\
\hline
\end{tabular}

$N$ is the number of experiments.

$R^{2}$ is the percent of the variation of the response explained by the model.

$R^{2} \mathrm{Adj}$ is the fraction of the variation of the response explained by the model adjusted for the degree of freedom.

$Q^{2}$ is the percent of the variation of the response predicted by the model.

$\mathrm{RSD}$ is the residual standard deviation.

By a COST approach we again identified the range for each parameter for the cell-containing capsules; afterwards a new DoE approach was performed with factors and responses reported in Table 3 and ANOVA analysis in Table 7. Evidently, a distance between the nozzle and the gelling bath of $140 \mathrm{~mm}$ was needed to obtain microcapsules with a regular shape and with the minor presence of tails and coalescences (Figures 6 and 7). At the end of the complete DoE study, we were able to identify a set of experimental parameters (reported in the last line of Table 8) resulting in the production of microcapsules with optimal characteristic for cell transplantation protocols, at least from a morphological point of view, such as, spherical shape, smooth surface, very narrow size distribution, absence of tails, and coalescences.

\section{In vitro Functions and In vivo Biocompatibility of NPI Containing Alginate Microcapsules}

Morphological and dimensional characteristics of the capsules as well as the coating integrity, before transplantation, were assessed by 

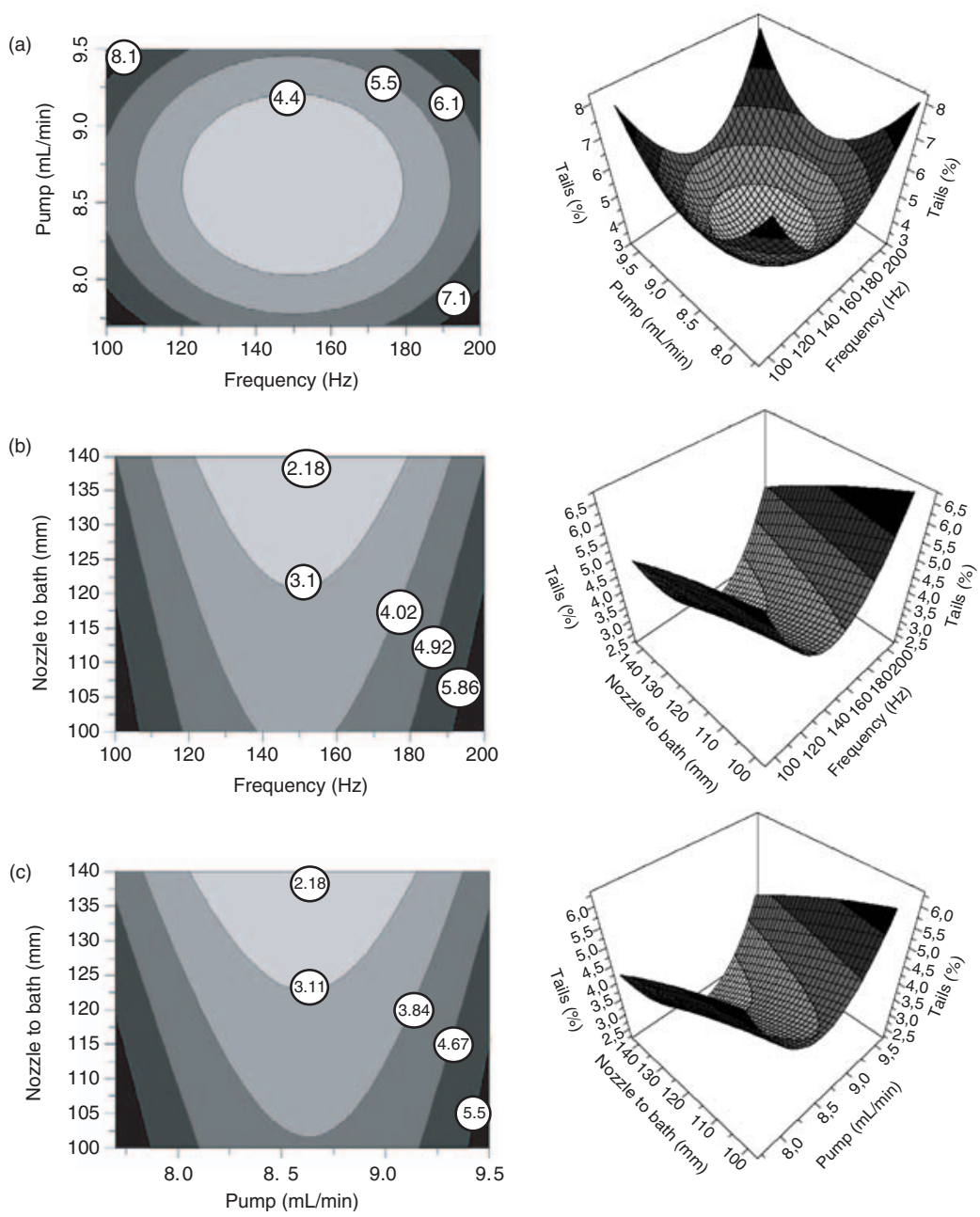

Figure 6. DoE analysis for alginate microcapsules encapsulating NPI. Contour plots (left side) and the corresponding response surface plots (right side) of the response 'tails' for the interaction between pump and vibrating frequency (a), nozzle to bath and vibrating frequency (b), and nozzle to bath and pump (c).

optical microscopy (Figure 8(a)-(c)). NPI were homogeneously distributed within the microcapsules, with the latter showing no appreciable morphological defects, such as 'tails', partial fusion or partial protrusion of the encapsulated cells. 

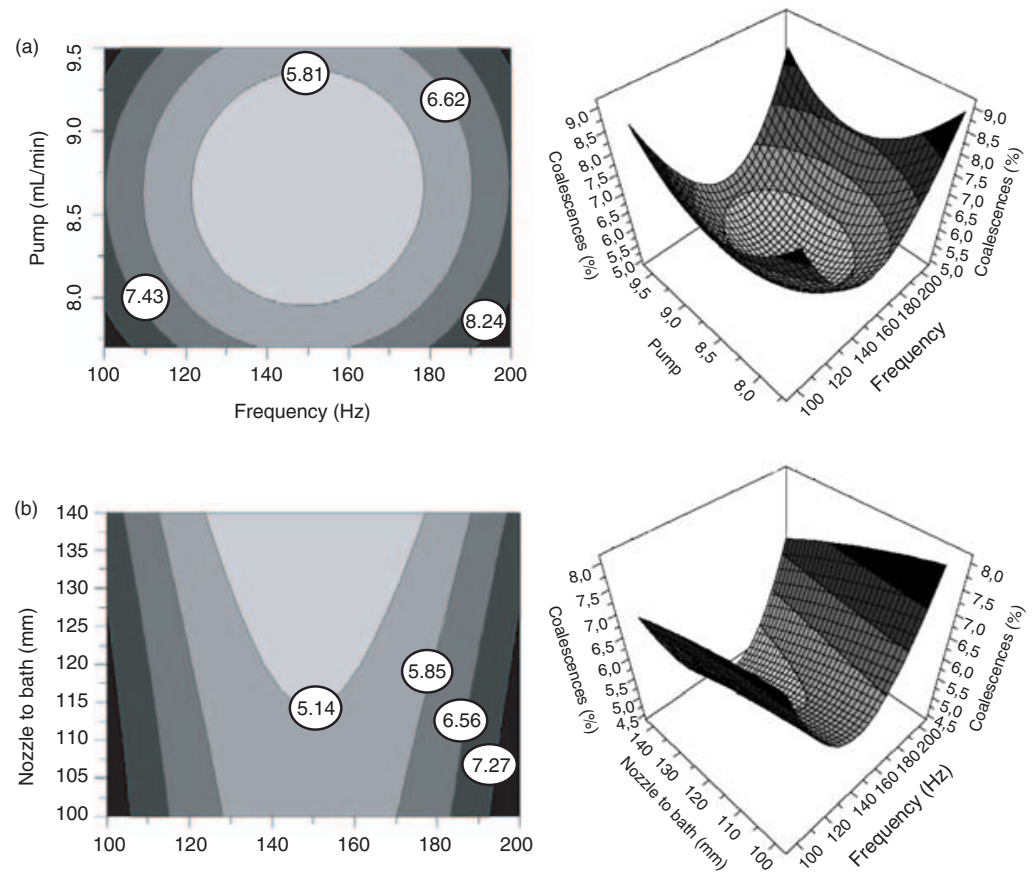

Frequency $(\mathrm{Hz})$
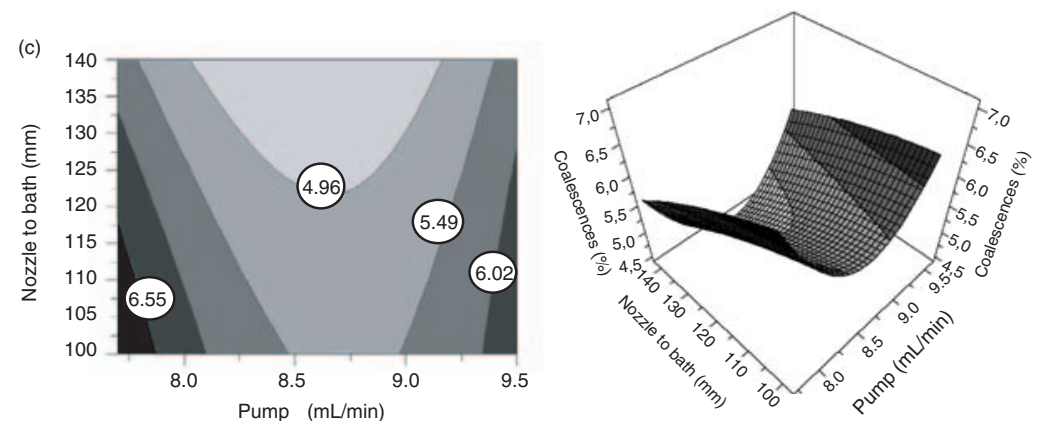

Figure 7. DoE analysis for alginate microcapsules encapsulating NPI. Contour plots (left side) and the corresponding response surface plots (right side) of the response 'coalescences' for the interaction between pump and vibrating frequency (a), nozzle to bath and vibrating frequency (b), and nozzle to bath and pump (c).

The fluorescence photomicrographs reported in Figure $8(\mathrm{~d})$ showed the viability of encapsulated NPI, after $24 \mathrm{~h}$ of cell culture, demonstrating that the cells were $>90 \%$ viable after the encapsulation. 
Table 8. COST (Changing One Separate factor a Time) analysis of the effect of the 'freq', 'amp', 'pump', and 'height' on the characteristics of NPI containing microcapsules.

\begin{tabular}{|c|c|c|c|c|c|c|c|}
\hline $\begin{array}{l}\text { Alginate } \\
\text { (w/v, \%) }\end{array}$ & $\begin{array}{l}\text { Frequency } \\
\quad(\mathrm{Hz})\end{array}$ & $\begin{array}{l}\text { Amplitude } \\
(\mathrm{mm})\end{array}$ & $\begin{array}{l}\text { Pump } \\
\text { (mL/min) }\end{array}$ & $\begin{array}{l}\text { Height } \\
(\mathrm{mm})\end{array}$ & $\begin{array}{c}\text { Tails } \\
(\%)\end{array}$ & $\begin{array}{c}\text { Coalesc. } \\
(\%)\end{array}$ & Surface \\
\hline \multicolumn{8}{|l|}{ Freq } \\
\hline 1.6 & 100 & 1 & 8.6 & 140 & $2-5$ & $5-10$ & Some wrinkles \\
\hline 1.6 & 150 & 1 & 8.6 & 140 & $<2$ & $<2$ & Some wrinkles \\
\hline 1.6 & 200 & 1 & 8.6 & 140 & $2-5$ & $5-10$ & Some wrinkles \\
\hline \multicolumn{8}{|l|}{ Amp } \\
\hline 1.6 & 150 & 1 & 8.6 & 140 & $<2$ & $<2$ & Some wrinkles \\
\hline 1.6 & 150 & 3 & 8.6 & 140 & $2-5$ & $5-10$ & Some wrinkles \\
\hline 1.6 & 150 & 6 & 8.6 & 140 & $2-5$ & $>10$ & Some wrinkles \\
\hline \multicolumn{8}{|l|}{ Pump } \\
\hline 1.6 & 150 & 1 & 7.7 & 140 & $2-5$ & $>10$ & Some wrinkles \\
\hline 1.6 & 150 & 1 & 8.6 & 140 & $<2$ & $<2$ & Some wrinkles \\
\hline 1.6 & 150 & 1 & 9.5 & 140 & $2-5$ & $5-10$ & Some wrincles \\
\hline \multicolumn{8}{|l|}{ Height } \\
\hline 1.6 & 150 & 1 & 8.6 & 100 & $2-5$ & $2-5$ & Irregular \\
\hline 1.6 & 150 & 1 & 8.6 & 120 & $<2$ & $2-5$ & Irregular \\
\hline 1.6 & 150 & 1 & 8.6 & 140 & $<2$ & $<2$ & Some wrinkles \\
\hline \multicolumn{8}{|l|}{ Selected } \\
\hline 1.6 & 150 & 1 & 8.6 & 140 & $<2$ & $<2$ & Some wrinkles \\
\hline
\end{tabular}

The morphological characteristics of microcapsules were assessed on at least 200 microcapsules/batch, considering the presence of (a) tails, (b) coalescences and (c) the surface characteristic. All the reported preparations were performed by a $60 \mathrm{~mL}$ syringe.

Data represent the average of three independent determinations on different microbead batches.

In order to compare the in vitro functions of free and encapsulated NPI, after 7 days of in vitro culture, the NPI insulin secretion was verified by staining the cells with DTZ (Figure 8(e)). As further control, we determined the endogenous insulin output of both free and encapsulated NPI under glucose stimulation. Figure 8(f) reported the insulin secretory patterns of free NPI (open bars) and alginate/ polyornithine microencapsulated NPI (hatched bars), during static incubation with glucose. Insulin levels were determined at low $(2.8 \mathrm{mmol} / \mathrm{L})$ and high $(16.8 \mathrm{mmol} / \mathrm{L})$ glucose concentration. As expected, incubation with high glucose increased the NPI's insulin secretory rate and the insulin levels between free and encapsulated NPI were significantly compared.

Finally, in order to evaluate the in vivo biocompatibility of alginate/ polyornithine. microencapsulated NPI were transplanted in the peritoneal cavity of rabbit as described in the experimental plan section. 

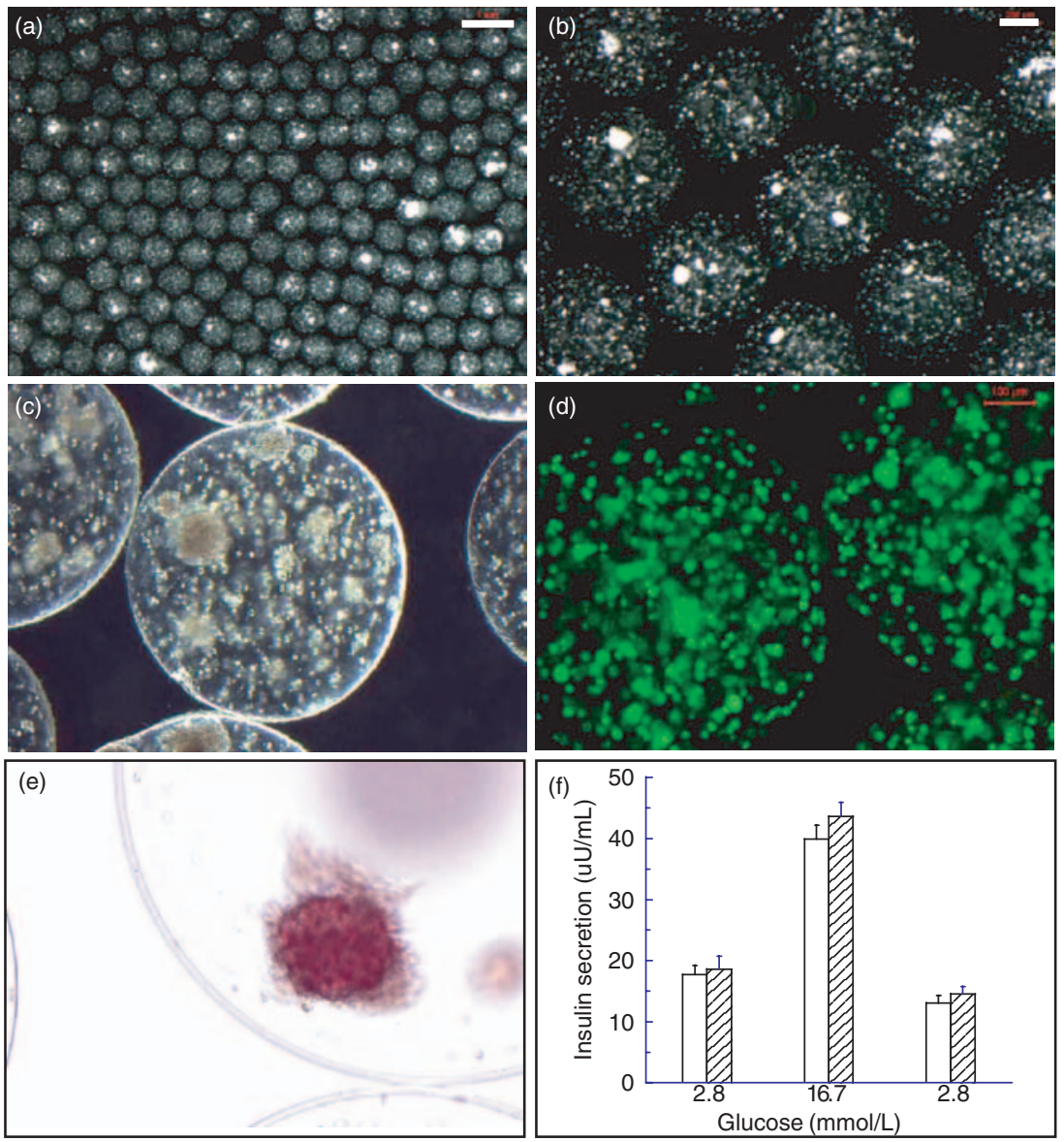

Figure 8. Optical photomicrographs of NPI encapsulating alginate/polyornithine microcapsules ((a)-(c) dark field); fluorescence photomicrographs of NPI encapsulating alginate/polyornithine microcapsules after staining with ethidium bromide and fluorescein-diacetate for islet cell viability (d); optical photomicrographs of NPI encapsulating alginate/polyornithine microcapsules after staining with DTZ for insulin detection (e), and finally in vitro insulin secretion profiles of free (hatched bars) and encapsulated NPI (open bars) under static incubation at the indicated glucose concentration at day 7 of the cell culture (f).

The obtained results, summarized in Figure 9, demonstrated that the capsules were freely floating in the peritoneal cavity of the rabbits (Figure $9(\mathrm{a}-\mathrm{c})$ ) and morphologically intact, with the majority of the microcapsules (over 85\%) appearing free of fibrotic tissue overgrowth at 3 months from transplant. 
In addition viability (Figure 9(d)) of the explanted microcapsules, containing NPI showed, at 3 months of transplantation, that the embodied NPI were extraordinary very viable.

\section{CONCLUSIONS}

Among the different procedures of encapsulation viable cells, the vibrational technique appears to be one of the most promising for the production of microcapsules in large scale GPL conditions. After COST and DoE studies we found that the optimized parameters to obtain NPI containing alginate were: vibrational frequency ('freq') $150 \mathrm{~Hz}$, vibrational amplitude ('amp') $1 \mathrm{~mm}$, alginate pumping rate ('pump') $8.6 \mathrm{~mL} / \mathrm{min}$ and distance between the nozzle and the surface of the gelling bath ('height') $140 \mathrm{~mm}$. In this respect, we were able to optimize the entire process of enveloping NPI in AG-based microcapsules with no loss of their functional and morphological properties either in vitro or in vivo conditions. The statistical analysis of the crucial experimental parameters of the vibrational encapsulation process may open new perspectives on the use, at industrial level of this protocol.
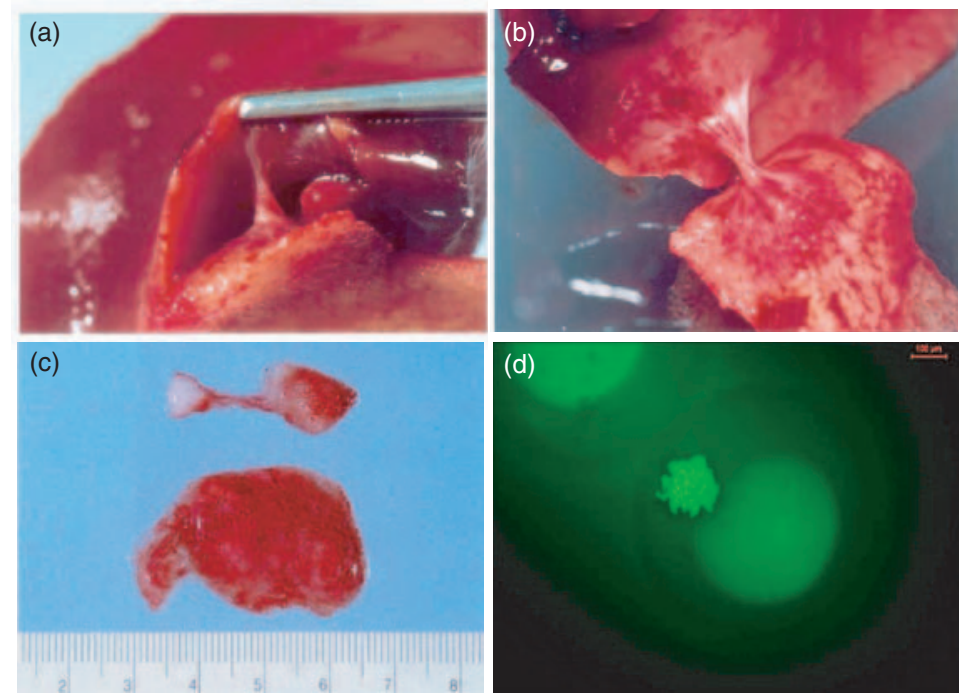

Figure 9. Biocompatibility of NPI containing alginate-based microcapsules transplated in the right lobo of a rabbit liver (a)-(c). Fluorescence photomicrograph of NPI encapsulated in alginate/polyornithine microcapsules after staining with ethidium bromide and fluorescein-diacetate upon retrieval from the peritoneal cavity of NOD mice (d). 


\section{REFERENCES}

1. Uludag, H., de Vos, P. and Tresco, P.A. (2000). Technology of Mammalian Cell Encapsulation, Advan. Drug Deliv. Rev., 42(1-2): 29-64.

2. Rabkin, J.M., Corless, C.L., Rosen, H.R. and Olyaei, A.J. (2000). Immunosuppression Impact on Long-term Cardiovascular Complications After Liver Transplantation, Am. J. Surg., 183(5): 595-599.

3. Park, J.K. and Chang, H.N. (2000). Microencapsulation of Microbial Cells, Biotechn. Advan., 18(4): 303-319.

4. Draget, K.I., Skjåk Bræk, G. and Smidsrød, O. (1997). Alginate Based New Materials, Intern. J. Biolog. Macrom., 21(1-2): 47-55.

5. de Vos, P., Faas, M.M., Strand, B. and Calafiore, R. (2006). Alginate-Based Microcapsules for Immunoisolation of Pancreatic Islets, Biomat., 27(32): 5603-5617.

6. Strand, B.L., Mørch, Y.A. and Skjåk Bræk, G. (2000). Alginate as Immobilization Matrix for Cells, Minerva Biotec., 12(4): 223-233.

7. Herrero, E.P., Martìn Del Valle, E.M. and Galàn, M.A. (2006). Development of a New Technology for the Production of Microcapsules Based in Atomization Processes, Chem. Eng. J., 117(2): 137-142.

8. Serp, D., Cantana, E., Heinzen, C., Von Stockar, U. and Marison, I.W. (2000). Characterization of an Encapsulation Device for the Production of Monodisperse Alginate Beads for Cell Immobilization, Biotech. Bioeng, 70(1): 41-53.

9. Brandenberger, H., Nüssli, D., Piëch, V. and Widmer, F. (1997). Monodisperse Particle Production: a New Method to Prevent Drop Coalescenze Using Electrostatic Forces, J. Electrostat., 45(3): 227-238.

10. Luca, G., Nastruzzi, C., Calvitti, M., Becchetti, E., Baroni, T., Neri, L.M., Capitani, S., Basta, G., Brunetti, P. and Calafiore, R. (2005). Accelerated Functional Maturation of Isolated Neonatal Porcine Cell Clusters: In Vitro and In Vivo Post-transplant Results in NOD Mice, Cell Transpl., 14(5): 249-261.

11. Korbutt, G.S., Elliott, J.F. and Rajotte, R.V. (1997). Cotransplantation of Allogeneic Islets with Allogeneic Testicular Cell Aggregates Allows Long Term Graft Survival without Systemic Immunosuppression, Diabetes, 46(2): 317-322.

12. Miyamoto, M., Morimoto, Y., Nozawa, Y., Balamurugan, A.N., Xu, B. and Inoue, K. (2000). Establishment of Fluorescein Diacetate and Ethidium Bromide (FDAEB) Assay for Quality Assessment of Isolated Islets, Cell Transplant., 9(5): 681-686.

13. Tye, H. (2004). Application of Statistical 'Design of Experimentss' Methods in Drug Discovery, Drug Discov. Today, 9(11): 485-491.

14. Carmona, M.E.R., da Silva, M.A.P. and Ferriera Leite, S.G. (2005). Biosorption of Chromium Using Factorial Experimental Design, Process Biochem., 40(2): 779-788. 